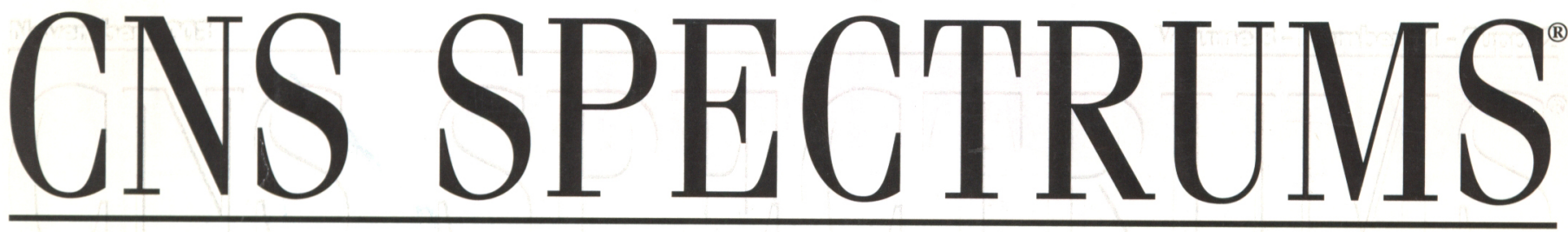

The International Journal of Neuropsychiatric Medicine

\title{
ACADEMIC SUPPLEMENT \\ Optimizing Treatment for Patients With Schizophrenia: Targeting Positive Outcomes
}

Introduction

D.E. Casey

The Science of Antipsychotics: Mechanistic Insight

C.A. Tamminga

Management of Acute Psychosis: From Emergency to Stabilization

D.L. Zimbroff

Beyond Control of Acute Exacerbation:

Enhancing Affective and Cognitive Outcomes

H.Y. Meltzer

Obesity, Diabetes, and Metabolic Syndrome:

New Challenges in Antipsychotic Drug Therapy

E. Caballero

Factors in Antipsychotic Drug Selection:

Tolerability Considerations

H.A. Nasrallah

Long-Term Treatment Goals: Enhancing Healthy Outcomes

D.E. Casey 


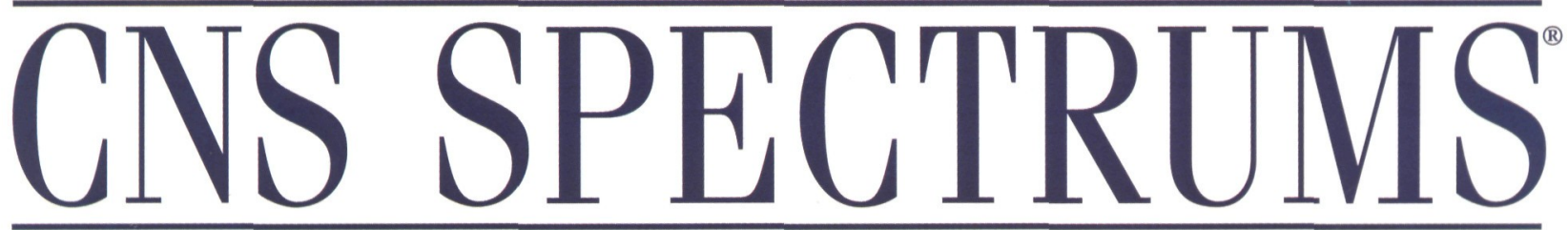

\section{The International EDITOR \\ Jack M. Gorman, MD \\ Mount Sinai School of Medicine \\ New York, NY}

\section{ASSOCIATE AND FOUNDING EDITOR}

Eric Hollander, MD

Mount Sinai School of Medicine

New York, NY

\section{INTERNATIONAL EDITOR}

Joseph Zohar, MD

Chaim Sheba Medical Center

Tel-Hashomer, Israel

\section{ASSOCIATE INTERNATIONAL EDITORS EUROPE}

Donatella Marazziti, MD

University of Pisa

Pisa, Italy

\section{MID-ATLANTIC}

Dan J. Stein, MD, PhD

University of Stellenbosch

Tygerberg, South Africa

\section{FAR EAST}

Shigeto Yamawaki, MD, PhD

Hiroshima University School of Medicine Hiroshima, Japan

\section{MEDICAL REVIEWER}

David L. Ginsberg, MD

New York University Medical Center New York, NY

\section{BOARD OF ADVISORS \\ NEUROLOGISTS}

Mitchell F. Brin, MD

University of California, Irvine

Irvine, CA

Jeffrey L. Cummings, MD

University of California, Los Angeles

Los Angeles, CA

Jerome Engel, Jr., MD, PhD

University of California, Los Angeles Los Angeles, CA

\section{Journal of Neuropsych}

Mark S. George, MD

Medical University of South Carolina Charleston, SC

Richard B. Lipton, MD

Albert Einstein College of Medicine Bronx, NY

C. Warren Olanow, MD, FRCPC

Mount Sinai School of Medicine New York, NY

Steven George Pavlakis, MD

Maimonides Medical Center

Brooklyn, NY

Stephen D. Silberstein, MD, FACP

Thomas Jefferson University

Philadelphia, PA

Michael Trimble, MD, FRCP, FRPsych National Hospital for Neurology and Neurosurgery

London, United Kingdom

\section{PSYCHIATRISTS}

Margaret Altemus, MD

Cornell University Medical College

New York, NY

Dennis S. Charney, MD

National Institute of Mental Health Bethesda, MD

Dwight L. Evans, MD

University of Pennsylvania

Philadelphia, PA

Siegfried Kasper, MD

University of Vienna

Vienna, Austria

Martin B. Keller, MD

Brown Medical School

Providence, RI

Lorrin M. Koran, MD

Stanford University School of Medicine

Stanford, CA

Yves Lecrubier, MD

Hôpital de la Salpêtrière

Paris, France

Herbert Y. Meltzer, MD

Vanderbilt University Medical Center Nashville, TN
Stuart A. Montgomery, MD

St. Mary's Hospital Medical School

London, United Kingdom

Charles B. Nemeroff, MD, PhD

Emory University School of Medicine

Atlanta, GA

Humberto Nicolini, MD, PhD

National Mexican Institute of

Psychiatry

Mexico City, Mexico

Stefano Pallanti, MD, PhD

University of Florence

Florence, Italy

Katharine Phillips, MD

Brown Medical Schoo

Providence, RI

Harold A. Pincus, MD

Western Psychiatric Institute \& Clinic

RAND-University of Pittsburgh Health

Institute, Pittsburgh, PA

Scott L. Rauch, MD

Massachusetts General Hospita

Charlestown, MA

Alan F. Schatzberg, MD

Stanford University School of Medicine

Stanford, CA

Thomas E. Schlaepfer, MD

University of Bonn

Bonn, Germany

Stephen M. Stahl, MD, PhD

University of California, San Diego

La Jolla, California

Norman Sussman, MD, DFAPA

New York University Medical School

New York, NY

Karen Dineen Wagner, MD, PhD

The University of Texas Medical Branch Galveston, TX

Herman G.M. Westenberg, MD

University Hospital Utrecht

Utrecht, The Netherlands

Stuart C. Yudofsky, MD

Baylor College of Medicine

Houston, TX

\begin{tabular}{ll}
\hline MBL COMMUNICATIONS Corporate Staff \\
CEO \& PUBLISHER & ACQUISITIONS EDITOR \\
\hline Darren L. Brodeur & Lisa Arrington \\
ASSOCIATE PUBLISHER & ASSISTANT ACQUISITIONS EDITOR \\
\hline Elizabeth Katz & Eilen S. Seligman \\
MANAGING EDITOR & EDITORIAL ASSISTANT \\
\hline Christopher Naccari & Shelley Wong \\
SENIOR EDITOR & PRODUCTION MANAGER \\
Deborah Hughes & Lila Moses \\
DEPUTY SENIOR EDITOR & GRAPHIC DESIGNER \\
José R. Ralat & Anthony J. Korsak \\
& CONTROLLER \\
& John Spano \\
\hline
\end{tabular}

NATIONAL ACCOUNT MANAGER

Kelly J. Staley

INFORMATION TECHNOLOGY

Greg Taube

OFFICE MANAGER

Claudette Crawford

OFFICE ASSISTANT

Manuel Pavón

CORPORATION COUNSEL

Lawrence Ross, Esq.

Bressler, Amery, and Ross

\section{EDITORIAL MISSION}

CNS Spectrums' editorial mission is to address relevant neuropsychiatric topics, including the prevalence of comorbid diseases among patients, and original research and reports that emphasize the profound diagnostic and physiologic connections made within the neurologic and psychiatric fields. The journal's goal is to serve as a resource to psychiatrists and neurologists seeking to understand and treat disturbances of cognition, emotion, and behavior as a direct consequence of central nervous system disease, illness, or trauma. 


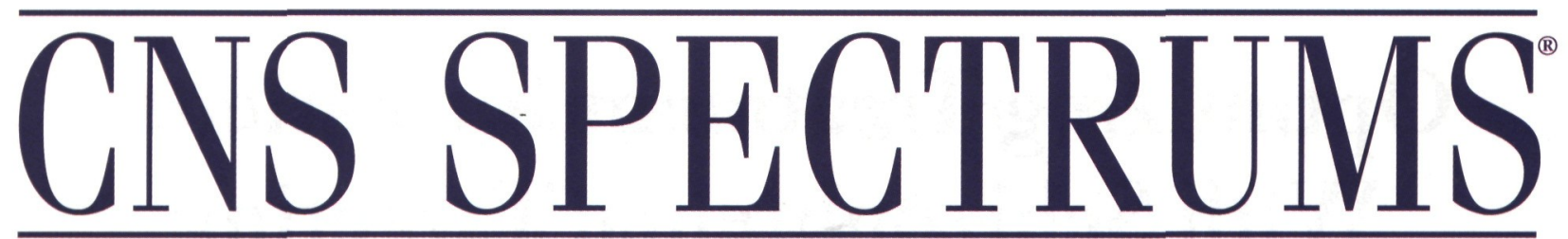

The International Journal of Neuropsychiatric Medicine

\section{Table of Contents}

November 2003

Volume 8 - Number 11 - Supplement 2

Based on Proceedings From the American Psychiatric Association Meeting Held May 17-22, 2003, in San Francisco, California

4 Introduction: Optimizing Treatment for Patients

With Schizophrenia

By Daniel E. Casey, MD

5 The Science of Antipsychotics: Mechanistic Insight

By Carol A. Tamminga, MD

10 Management of Acute Psychosis: From Emergency to Stabilization

By Dan L. Zimbroff, MD

16 Beyond Control of Acute Exacerbation:

Enhancing Affective and Cognitive Outcomes

By Herbert Y. Meltzer, MD

19 Obesity, Diabetes, and Metabolic Syndrome:

New Challenges in Antipsychotic Drug Therapy

By Enrique Caballero, MD

23 Factors in Antipsychotic Drug Selection:

Tolerability Considerations

By Henry A. Nasrallah, MD

26 Long-Term Treatment Goals: Enhancing Healthy Outcomes

By Daniel E. Casey, MD

\section{CONTINUING MEDICAL EDUCATION}

29 This CME quiz on schizophrenia is accredited by Mount Sinai School of Medicine for 3 credit hours in Category 1.
CNS Spectrums is an Index Medicus journal and is available on MEDLINE under the citation CNS Spectr.

It is also indexed by DIALOG, EMBASE/Excerpta Medica, ÓVID, Lexis-Nexis, and SilverPlatter.

CNS Spectrums ${ }^{\circledast}$

(ISSN 1092-8529)

is published monthly by MBL Communications, Inc. 333 Hudson Street, 7th Floor New York, NY 10013

One year subscription rates: domestic $\$ 120$;

foreign $\$ 185$;

in-training $\$ 75$.

For subscriptions, Fax: 212-328-0600

Web site: www.cnsspectrums.com

For editorial inquiries:

dh@mblcommunications.com

Postmaster:

Send address changes to

CNS Spectrums

clo PPS Medical Marketing Group

264 Passaic Avenue

Fairfield, NJ 07004-2595

Opinions and views expressed by authors are their own and do not necessarily reflect the views of the publisher, MBL Communications, Inc., or the editorial advisory board.

CNS Spectrums $\circledast$ is a registered trademark of CNS Spectrums, LLC, New York, NY.

Permission to reproduce articles in whole or in part must be obtained in writing from the publisher.

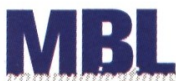

Copyright $\odot 2003$ by MBL

Communications, Inc. All rights reserved.

Printed in the United States. Disclaimer

This academic supplement is supported via an unrestricted educational grant from Pfizer Inc. Sponsorship of this review does not imply the sponsor's agreement with the views expressed herein.

Although every effort has been made to ensure that drug doses and other information are presented accurately in this publi. cation, the ultimate responsibility rests with the prescribing physician. Neither the publisher, the sponsor, nor the authors can be held responsible for errors or for any consequences arising from the use of information contained herein. Readers are strongly urged to consult any relevant primary literature. No claims or endorsements are made for any drug or compound currently under clinical investigation.

In an effort to allow for the widest distribution of these guidelines, the authors have modified the originally printed material to more closely conform to the limitations of product labeling. For many of the drugs discussed herein, initiation at lower doses may increase tolerability and efficacy. 